\title{
BUILDING ON TRANSIENCE: TOLERANCE AND THE SUBJECTIVE DIMENSIONS OF TECHNOLOGY
}

\author{
WILLIAM M TAYLOR \\ Faculty of Architecture, Landscape \& Visual Art \\ University of Western Australia, Perth \\ 35 Stirling Highway, Crawley, WA 2009, Australia \\ btaylor@cyllene.uwa.edu.au
}

\begin{abstract}
Technology acquires a provocative charge in different ways, one arising from observations of 'transience' in the built environment, particularly of the life and performance of buildings over time, their conception and construction, use and performance, inevitable failure or decay. Technological systems can be particularly thought provoking when human expectations and actions are implicated in the performance of buildings - which, of course, is always. This paper discusses how building technology (its conception, operation and valuation) is mediated by an ethical imperative aimed at managing change and the uncertainties it poses and from which an understanding of identity, character and values may be derived.

The concept of operational 'tolerance' draws our attention to the capacity of building technologies to articulate change and perform according to varied physical and aesthetic expectations. Expectations might be said to include those for a certain kind of structural soundness and integrity or visual clarity. A failure to fulfil these serves to draw our attention yet further to particular environmental and even social circumstances which characterise, inhibit or enhance the operation of architectural medium - like unstable soils, pervious or defective building materials, poor workmanship or even extremes of weather and neglect. The concept of tolerance is related to the governance and normalisation of habitable space in modern times though has precursors in other times and varied modes of construction. Here it is cast as a useful analytical tool for understanding transience and the built environment in terms of technology and for describing the patterns of sensibility and self-awareness arising from an experience of technological systems.
\end{abstract}

Keywords: transience, tolerance or operational tolerance, technological transfer, identity, character, values.

\section{Introduction}

This paper forms part of a broader research project on transience and the built environment. The thesis underlying this project is that transience, understood alternatively as i) a state of change characterising one thing or another (phenomenal transience) or ii) an apprehension of the impermanence of all things - their inevitable changefulness, fallibility or passing away (existential transience) - has been and remains a key feature of human experience. Relations 
between these two understandings of transience are neither accidental nor simply metaphorical; there are additional conceptual as well as technological circumstances relating the one to the other. Serving as a register of everyday expectations and anxieties associated with science and related practical and industrial arts, for instance, technology is regularly called upon to ameliorate the consequences of time's passage in multiple spheres of human experience. However, the prospect of better science and more technology does little to allay apprehension that our tools, machines and buildings invariably break down or fail to perform the way they should or that other circumstances may arise in the future to complicate the tasks they were meant to perform. At one extreme of a scale of conceivable malfunctions, the phrase 'catastrophic failure' has been coined to describe circumstances in which technological systems, particularly and most spectacularly structural systems, undergo a complete, typically sudden failure from which their recovery is unlikely. Compared to expectations likely to characterise a pre-industrial age, the fallibility of human tools and industry (and humans themselves) has become as much a 'fact' of life today as the finitude of life itself.

Among the possible ways that building technology and its performance might be seen to engage change and lead to an understanding of human subjectivity, this paper is counterpoised by, and largely rejects one particular perspective as narrow and untenable. It is a perspective which takes technology to comprise a broad category of human means and intentions (sciences, industrial and practical arts) that threaten to alienate human beings from some other, supposedly 'natural' or truly meaningful state of existence and belonging. This figure that comes most clearly to mind who espouses such a view is Alberto Perez-Gomez, though others like Dalibor Vesely and Karsten Harries share it in some measure. Perez-Gomez implicates patterns of sensibility, self-awareness and mutual understanding in a hypothetical 'poetic' dimension of building; a claim which is metaphysical and grounded in the transcendental phenomenology of Edmund Husserl. Perez-Gomez writes ("Built", 3-4) in the introduction to his most recent book:

"This book argues that the materialistic and technological alternatives for architecture however sophisticated and justifiable they may be, in view of our historical failures - do not answer satisfactorily to the complex desire that defines humanity. As humans, our greatest gift is love, and we are invariably called to respond to it. Despite our suspicions, architecture has been and must continue to be built upon love. I will endeavour to show how this foundation possesses it owns rationality, one that the built environment will not follow if it is based on premises drawn from normative disciplines or abstract logical systems. While recognizing the dangers of traditional religions, moral dogmas, and ideologies, true architecture is concerned with far more than fashionable form, affordable homes, and sustainable development; it responds to a desire for an eloquent place to dwell, one that lovingly provides a sense of order resonant with our dreams, a gift contributing to our self-understanding as humans inhabiting a mortal world."

The passage calls upon a universal and timeless (by and large essentialist) view of human identity; references to basic desires and the need for dwelling animate the book and call to mind popular concepts of place and concerns for Heidegger's conceptual couplet of building and dwelling. With an emphasis on placefulness and being and by downplaying change, contingency and risk (except to diagnose the latter as ills), these concerns are inadequate to describe the multiple impacts of transience on human character and values. In the passage, changefulness and the multiple forms of change conceivably manifest, impeded or enhanced by buildings are largely downplayed. Instead, the author seeks a static condition in which the forms and functions buildings and building technology are reconciled by the dutiful and poetically-minded designer in pursuit of 'true architecture' (Perez-Gomez). The view of identity acquired by such a perspective is largely eschatological and basically fundamentalist. To the contrary, this paper evinces a view that is more multi-faceted and historically-grounded and less in need of metaphysical support. It does not cast material concerns and technological systems as one category of means and intentions amongst a number of 'alternatives' for architecture. Unlike Perez-Gomez's book it is not a discourse on 'love' or any perversion of the term, Greek or otherwise ("logical", "affordable" or "sustainable"); it does not engage archaic ideas and practices to support its claims. Rather, the paper aims to show that materials and technology, particularly when part of 'normative' disciplines can be productive of self-awareness and understanding in positive, ethical ways. Though dismissed by Perez-Gomez and his disciples, technology can be one means of finding our place in this "mortal world."

In view of the broad scope of this research project and a potentially large source of illustrative material available from the history of science and technology, this paper narrows its themes by describing one key concept and a number of historical references to illustrate it. It focuses on 
the performance of technological systems and their operation and human reaction to their reliability (or otherwise), by way of describing the concept of 'tolerance' as a potentially useful analytical tool. It is a tool whereby both understandings of transience are drawn together and from which forms of awareness (environmental and ethical) constitutive of identity may be derived. Qualified by adjectives like 'operational', 'technical' or 'mechanical' or, most commonly in architectural practice, 'building' (or 'builder's'), the term 'tolerance' denotes the margins of error or workmanship determining whether or not a device, machine or manufactured material, building product or practice fulfils its intended purpose or achieves a desired result, structurally or aesthetically or in some other way. The paper aims to show that by acknowledging these margins a person may also be admitting something about themselves - their own limitations, perhaps, or prospects for further creative and practical endeavour.

\section{Operational Tolerance}

The concept of 'tolerance' offers one way to think about the interaction of both phenomenal and existential transience given the mediation, design and human experience of technological systems. Common to everyday language, but also reflecting the particular concerns of moral philosophy and theology, medicine and biology, the term 'tolerance' has long denoted the 'performative constitution' (OED) of a thing - most commonly, of a person with a capacity to endure pain or hardship or someone able to withstand particular doses of medicines, poisons or drink. Each of these manifestations of tolerance (or conceivably, intolerance) draws on a temporal framework and likewise implicates the perceptions of change - in oneself, one's companions or one's surroundings. For instance, a person is praised for enduring a life of hardship or for acquiring the related values of patience and forbearance as these become apparent only over time. A capacity for withstanding the effects of one or the other consumed substances may be inherited or acquired and so, implicates life experiences (geneticallyattuned or habitual) of varying duration. In either case, consequently, it may be claimed that one comes to exhibit a tough or relatively feeble constitution for resisting or exacerbating those agents, persons or things which inevitably impact upon someone. From observations of innumerable instances of resistance or acquiescence one might draw broader lessons of the meaning of existence itself - that life is hard, for instance, unpredictable and risky.

Of more recent derivation and owing to the history of industrialisation and empirical science, the growth and differentiation of technological systems, operational (encompassing technical, mechanical or building forms as well) tolerance transposes what was once an attribute of living things onto machines or objects of human and industrial manufacture. Machines 'normally' tolerate or perform as expected if margins of error in workmanship are followed or certain physical, geometrical or environmental conditions satisfied. This is, in fact, partly what makes technology normalising in ways described by Georges Canguilhem (370-378): instrumentally and systematically, behaviourally, cognitively and ethically. The 'performative constitution' of a manufactured object connects the thing to yet other objects and machines - those which first produced it or which, in turn, may be used by it - as part of a system within which devices are used and through which they acquire operative as well as other kinds of non-operative (like semantic and moral) values. In relation to manufacture, the term 'tolerance' first appears in English usage, according to the Oxford English Dictionary, in relation to minting and the standardisation of coinage. The "small margin within which coins, when minted, are allowed to deviate from the standard fineness and weight" (OED) contributed to the stabilization of worldwide currency exchange in the nineteenth century and contributed to an economic order governed by monetary agencies and international agreements. This first, internationallysanctioned tolerance was, plus or minus, one-sixteenth of a carat or 15 grains (approximately $972 \mathrm{mg}$ ) for the fineness or quality of the metal and 12 grains $(777.586 \mathrm{mg})$ for weight for each troy pound (5760 grains or approximately 373.24 grams) of coin. The principle can be seen at work with many of the first objects of standardised manufacture, particularly those which were widely valued and commonly traded, their parts readily replaced or interchanged. The manufacture of rifles is one case in point. The margin for error in workmanship and performance required to produce and use rifles and other military hardware can be related to such phenomena as the codification of ballistics, the re-incorporation of infantry and its disciplines into modes of modern warfare and even calculations of strategic advantage between rival states with large (now industrialised) armies.

Such relations not only underscore the systemic character of most technology (not only military hardware) generally, they also identify structures or avenues of a kind - comprising discourses and disciplines, calculative and governmental regimes - that facilitate the process commonly called 'technological transfer'. Commonly cited instances of this phenomenon include the 
transfer of aluminium technology from military to civilian aviation industries following the Second World War. It begins to explain how plastics, developed in part to remedy the shortages of naturally-occurring raw materials during wartime, found innumerable uses (many, newly created) in a range of industries afterwards (Philips). More recently, an instance of technological or material transfer is the movement of large stocks of titanium, reserved for weapons production during the Cold War, onto the open market for building supplies. While not exactly the turning of a sword into a ploughshare, the metal has been transformed into a Guggenheim museum or two (so far) and countless executive toys. When accounting for why these transfers were successful, it is perhaps less significant that one or the other person had the idea that aluminium, plastic or titanium might have a novel use. Rather, it is important is that there were means available (scientific and industrial, corporate and governmental) for allowing such ideas to be acted upon - to effect the transfer of material or manufactured goods, in other words, from one use to another. Change of this phenomenal kind, facilitated by these overlapping conceptual, practical and institutional contexts, contributes to apprehension of a world of further possibility, creative and practical endeavour.

Meanings of 'tolerance' have come to include the performative dimensions of manufactured objects as well as to denote a character trait of human beings. At the same time the concept of operational tolerance has served to further heighten a domain of human sensibility (one might call this a focus for self-awareness) where technology raises questions of identity, character and values - humankind being the principle devisor, user and ultimately, the beneficiary (as well as a chief victim) of the tools they devise. Among other things, a person may now be obliged to be tolerant of their tools. Chief among the forms of self-awareness engendered by the use of technology are those accompanying what lan Hacking calls the taming of chance. This is where, in view of the many tasks technological systems might perform, more or less adequately, there arises apprehension of those circumstances in which technology does or most likely will fail. These occasions are a challenge to normal expectations for the predictability and reliability of technology brought into play as people attempt manipulate nature for human benefit. They lead on to questions of whether one is able to or should do so - questions of the limits of scientific expertise, technological prowess and ultimately, human agency and of the tolerability of overstepping certain limits (as in the case of accidents).

\section{Tolerance and Environmental Awareness}

One form of self-awareness is the kind of prescience that comes from being conscious of one's surroundings. An experience of technology has a bearing on this too. This seems a particularly important issue to highlight by way of drawing this paper to a close and in view of current environmental problems, their likely cause in unrestrained industrialisation and their hopeful solution in yet more human industry, better science and sustainable technologies. Environmental concerns are broadly implicated by the first understanding of tolerance (a constituent part of selfhood) described earlier in the paper. Historically, though most clearly since the time of Francis Galton, human character - including potential character traits like tolerance, patience and forbearance - have come to be seen as dependant upon a person's unique constitution and a history of adaptations, more or less effectively, to specific environs. These environs include both natural and social circumstances determining human vitality whether a person strives or withers.

Equally, the normality, behavioural and self-reflective aspects of technological systems implicate natural and social contexts brought into focus by the concept of operational tolerance. Instances of catastrophic failure are often a consequence of either the unforseen physical behaviour of materials or cataclysmic, environmental circumstances in which their performative limits have been exceeded. Investigations of material fatigue, being an instance of the former, have come about largely in response to the long-term use of devices like steel ships or aluminium aircraft or, more humbly, the repeated unbending and bending of paperclips by anxious office workers. The kind of progressive damage done to materials due to minimal, cyclic or fluctuating loads which are oftentimes much less than their static yield strength is evident in the famous collapse of the Tacoma (Washington, USA) Narrows Bridge in 1940, a consequence, it was subsequently determined, of wind-induced vibrations. This episode prefigures others, most notably, the unexpected swaying of London's Millennium Bridge designed and engineered by Arup, Foster and Partners and sculptor Anthony Caro, a phenomenon more disquieting than potentially catastrophic due to the synchronous lateral excitation of the bridge caused by the footfalls of pedestrians.

Of cataclysmic environmental events which have led structural systems to undergo a complete and sudden failure, the collapse of concrete freeways during the 1989 Loma Prieta earthquake 
in the San Francisco Bay area was attributed to a seismic-related phenomenon called soil liquefaction. Another, the widespread shattering of curtain-wall glazing on high-rises across downtown Houston in 1983, was due to an unprecedented differential in air pressure caused by the passing of hurricane Alicia. Whether due to material failure or environmental circumstances, instances of catastrophic failure gives one cause to doubt the potential for human understanding to fully comprehend how nature, its elements or 'departments' truly works (Taylor). This kind of insight into the human condition can lead to the acceptance or rejection of certain values. It can lead one to acquiesce to the 'laws' or pre-eminence of nature or to reject, wholly or partly, positive claims made on behalf of technological systems by their engineers, manufacturers and salespeople or other self-interested parties with a stake in the buildings they give rise to (like the developers of high-risers in cities like Houston). Environmental and selfawareness can also arise from and contribute to apprehension of the novelty value, not so much of life-threatening cataclysms perhaps, but of less-threatening, technical malfunctions. Having reason to doubt ourselves when confronting nature with dubious technological fixes, their failure can nonetheless be a prompt for yet further invention - encouraging further hope that things can be made all right.

\section{Conclusion}

Operational tolerance is a useful analytical tool, to be placed alongside others leading to understanding of the physical and philosophical, historical and social dimensions of technological systems. It is particularly suited for more extended study of building technology than has been permitted by this paper as buildings, the ways they are built and the materials that comprise them, impact on most, if not all aspects of life. Consideration of their 'performative constitution' draws our attention to the expectations and anxieties manifest by building systems and materials as well as their physical attributes, structural or aesthetic aspects. It draws out attention to how systems manifest, impede or enhance an experience of change in a phenomenal sense as well as encourage other kinds of thoughts on their (and our own) fallibility and probable failure. Understanding how these sensibilities contribute to forms of awareness challenge other, narrow, metaphysically-grounded theories of architecture. The view of a fixed, universal or timeless character to human identity implicated by the work of PerezGomez and others can be challenged with a broader understanding of how human beings devise and experience their tools and technical capabilities and are consequently impacted upon them, both positively and negatively.

\section{References}

Canguilhem, Georges. A Vital Rationalist: selected writings from Georges Canguilhem. François Delaport (ed.); transl. Arthur Goldhammer; introduction Paul Rabinow. NY: Zone Books, 1994.

Galton, Francis. Hereditary Genius. London: MacMillan, 1869.

Hacking, lan. The taming of chance. Cambridge: Cambridge University Press, 1990.

Harries, Karsten. The ethical function of architecture. Cambridge, MA \& London: The MIT Press, 1997.

Heidegger, Martin. "Building, Dwelling, Thinking." Translated and with an introduction by Albert Hofstadter. Poetry, language, thought. New York: Harper Colophon Books. 145-161.

Husserl, Edmund. The crisis of European sciences and transcendental phenomenology. Evanston, ILL: University of Illinois Press, 1960.

Perez-Gomez, Alberto. Architecture and the crisis of modern science. Cambridge, MA and London: The MIT Press, 1983.

--- Built upon Love: architectural longing after ethics and aesthetics. Cambridge, MA and London: The MIT Press, 2006.

Phillips, Steven. "Plastics." Beatriz Colomina, Ann Marie Brennan and Jeannie Kim (eds). Cold War Hothouses: Inventing Postwar Culture from Cockpit to Playboy. New York: Princeton Architectural Press, 2004: 91-123.

Taylor, William. The Vital Landscape: nature and the built environment in nineteenth-century England. Aldershot (London): Ashgate, 2004.

Transience. Oxford English dictionary online. Oxford: Oxford University Press, 2000.

Vesely, Dalibor. "Architecture and the Conflict of Representation." AA Files 8 Jan. 1985. 